\title{
Early efficacy of budesonide/formoterol in patients with moderate-to-very-severe COPD
}

\author{
This article was published in the following Dove Press journal: \\ International Journal of COPD \\ 19 December 2016 \\ Number of times this article has been viewed
}

\author{
Peter M Calverley' \\ Göran Eriksson ${ }^{2}$ \\ Christine $R$ Jenkins ${ }^{3}$ \\ Antonio R Anzueto ${ }^{4}$ \\ Barry J Make ${ }^{5}$ \\ Anders Persson ${ }^{6}$ \\ Malin Fagerås ${ }^{6}$ \\ Dirkje S Postma ${ }^{7}$ \\ 'Pulmonary and Rehabilitation \\ Research Group, University Hospital \\ Aintree, Liverpool, UK; ${ }^{2}$ Department \\ of Respiratory Medicine and \\ Allergology, University Hospital, Lund, \\ Sweden; ${ }^{3}$ George Institute for Global \\ Health, The University of Sydney and \\ Concord Clinical School, Sydney, \\ Australia; ${ }^{4}$ Department of Pulmonary \\ Medicine and Allergology, University \\ of Texas Health Sciences Center and \\ South Texas Veterans' Health Care \\ System, San Antonio, Texas, ${ }^{5}$ Division \\ of Pulmonary Sciences and Critical \\ Care Medicine, National Jewish \\ Health, University of Colorado, \\ Denver, Colorado, USA; ${ }^{6}$ AstraZeneca \\ R\&D, Gothenburg, Sweden; \\ ${ }^{7}$ Department of Pulmonary Medicine \\ and Tuberculosis, GRIAC Research \\ Institute, University Medical Center \\ Groningen, University of Groningen, \\ Groningen, the Netherlands
}

Correspondence: Peter M Calverley Department of Clinical Sciences, Institute of Aging and Chronic Disease, University Hospital Aintree, Lower Lane, Liverpool L9 7AL, UK

Tel +44 I5I 5295886

Fax +44 I5I 5295888

Email pmcal@liverpool.ac.uk
Background and objective: Large clinical trials have confirmed the long-term efficacy of inhaled corticosteroid/long-acting $\beta_{2}$-agonist combinations in patients with chronic obstructive pulmonary disease (COPD). It was hypothesized that significant treatment effects would already be present within 3 months after the initiation of treatment across a range of clinical outcomes, irrespective of COPD severity.

Methods: Post hoc analysis of 3-month post-randomization outcomes, including exacerbation rates, dropouts, symptoms, reliever use, and lung function, from three studies with similar inclusion criteria of moderate-to-very-severe COPD. Patients $(n=1,571)$ were treated with budesonide/formoterol (B/F) 320/9 $\mu \mathrm{g}$ or placebo, twice daily; in one study, tiotropium $18 \mu \mathrm{g}$ once daily was also given.

Results: Over the first 3 months of treatment, fewer patients randomized to $\mathrm{B} / \mathrm{F}$ experienced exacerbations versus the placebo group (111 and 196 patients with $\geq 1$ exacerbation, respectively). This was true in each COPD severity group. Compared with placebo, B/F treatment led to significantly lower 3-month exacerbation rates in the moderate and severe COPD severity groups (46\% and 57\% reduction, respectively), with a nonsignificant reduction (29\%) in very severe COPD. Fewer dropouts occurred among patients treated with B/F versus placebo, this effect being greater with increasing COPD severity. B/F was associated with improved forced expiratory volume in $1 \mathrm{~s}$, morning peak expiratory flow rate, total reliever use, and total symptom score versus placebo.

Conclusion: Treatment with $\mathrm{B} / \mathrm{F}$ decreased exacerbations in patients with moderate-tovery-severe COPD within 3 months of commencing treatment. This effect was paralleled by improved lung function, less reliever medication use, and fewer symptoms, irrespective of disease severity.

Keywords: bronchodilator agents, clinical respiratory medicine, clinical trials, COPD

\section{Introduction}

Chronic obstructive pulmonary disease (COPD) remains a major cause of ill health worldwide and is the third most common cause of death. ${ }^{1,2}$ In the last decade, a series of large clinical trials have provided the evidence base for current drug treatment of COPD,${ }^{3-5}$ and these findings have been incorporated into treatment guidelines. ${ }^{6}$ These studies resolved many questions about the effect of drugs on individual outcomes. However, there are limited data that indicate how quickly improvement becomes evident following the initiation of treatment, and that describes the factors that influence early responses to treatment.

In many COPD trials lasting $\geq 1$ year, the first clinical visit occurred 3 months after randomization, but results are reported for the whole study duration. ${ }^{3,7}$ Analysis of diary-card data from the initial long-acting $\beta_{2}$-agonist (LABA) and inhaled 
corticosteroid (ICS) trials in COPD established that treatment improves peak expiratory flow (PEF) rate and symptoms within 2 weeks of initiation, a change that was more rapid when the LABA and ICS were given together. ${ }^{8,9}$ However, the early impact of treatment on exacerbations and disease control, that is, within 3 months of randomization, was not formally evaluated in these trials. Additionally, in many studies, the impact of disease severity on response to treatment was not considered, for instance, in the 3-month CLIMB study in which patients received budesonide/formoterol in addition to tiotropium. ${ }^{10}$ The effect of disease severity was assessed in patients receiving salmeterol and fluticasone propionate, alone or in combination, in the TORCH study, where worse disease severity as assessed by spirometry was associated with a greater likelihood of having an exacerbation but was not related to the overall treatment effects. ${ }^{11}$

It was hypothesized that significant treatment effects would be present across a range of clinical outcomes within 3 months of budesonide/formoterol (B/F) initiation and that these differences would be independent of the severity of spirometric impairment. To test these hypotheses, data were pooled from three previously reported studies confirming the efficacy of the ICS/LABA B/F in patients with COPD. ${ }^{9,10,12}$

\section{Methods}

\section{Study design}

A post hoc analysis of 3-month data from three studies of patients with moderate-to-very-severe COPD is reported; complete details of these studies are reported elsewhere., ${ }^{9,10,12}$ The studies recruited outpatients aged $\geq 40$ years with $\geq 10$ pack-years smoking history, COPD symptoms for $\geq 2$ years, forced expiratory volume in $1 \mathrm{~s}\left(\mathrm{FEV}_{1}\right) /$ vital capacity $(\mathrm{VC})$ ratio $\leq 70 \%$, pre-bronchodilator $\mathrm{FEV}_{1} \leq 50 \%$ predicted, and history of $\geq 1$ COPD exacerbation within 1-12 months of inclusion. All participants provided written informed consent. Ethical approval was obtained for each of the studies included in this analysis ${ }^{9,10,12}$ from local Independent Ethics Committees in each of the participating countries.

This analysis included patients treated with $\mathrm{B} / \mathrm{F}$ (Symbicort $^{\circledR}$ Turbuhaler $^{\circledR}$; AstraZeneca, Sweden) 320/9 $\mu \mathrm{g}$ twice daily (two inhalations of $160 / 4.5 \mu \mathrm{g}^{9,12}$ or one inhalation of $320 / 9 \mu \mathrm{g}^{10}$ ) or placebo twice daily. In the CLIMB study, ${ }^{10}$ study medications were given in addition to tiotropium $18 \mu \mathrm{g}$ once daily. As-needed terbutaline $0.5 \mathrm{mg}$ /inhalation (Bricanyl $^{\circledR}$ Turbuhaler $^{\circledR}$; AstraZeneca) was permitted as reliever medication throughout all the studies.

Spirometric severity of COPD was classified as moderate $(<80 \%$ to $\geq 50 \%$ predicted $)$, severe $(<50 \%$ to $\geq 30 \%$ predicted), or very severe ( $<30 \%$ predicted), according to GOLD 2016 post-bronchodilator $\mathrm{FEV}_{1}$ grading criteria. ${ }^{6}$

\section{Study variables}

In the studies included in this post hoc analysis, exacerbations were defined as worsening of COPD leading to oral corticosteroids, alone or in combination with antibiotics, and/or hospitalization/emergency room visits. Exacerbations leading to antibiotics alone from two studies ${ }^{9,12}$ were excluded from the analysis in order to achieve a common definition of exacerbations. The number of patients who dropped out from the studies (for any reason, including exacerbations) was also recorded. Lung function was recorded as pre-dose $\mathrm{FEV}_{1}(\mathrm{~L})$ at study visits (at weeks 1,6 , and $12^{10}$ or at months 1,2 , and $3^{9,12}$ ), and daily morning PEF (L/min) was collected from electronic diaries ${ }^{10}$ or diary cards $s^{9,12}$ of the patients. Reliever medication use (inhalations/day) and symptoms of dyspnea, cough, chest tightness, and night time awakenings (assessed on a 5 -point scale; $0-4$, where $4=$ severe symptoms) were also recorded in patient diaries and collected at clinic visits.

\section{Statistical methods}

Patient demographics and baseline characteristics are presented descriptively. All variables were analyzed by disease severity and treatment. The 3-month rates of exacerbations were assessed using Poisson regression analysis, with study and treatment as factors, and the number of days in the study as an offset variable. Over-dispersion was assessed in each model by calculating the ratio of the model deviance to its number of degrees of freedom. These analyses utilized only actual recorded data and did not impute for missing data. The rate (and rate ratios [RR]) of exacerbations within 3 months and corresponding 95\% confidence intervals (CIs) were presented. Percentage reductions in exacerbation rates with $\mathrm{B} / \mathrm{F}$ versus placebo were also presented, which were derived from the rate ratio. The number of patients with at least one exacerbation and dropouts were presented descriptively. Subsequent analyses included change from baseline in $\mathrm{FEV}_{1}(\mathrm{~L})$, morning PEF (L/min), reliever use (inhalations/day), and total symptom scores and were analyzed using analysis of covariance to estimate the treatment differences between $\mathrm{B} / \mathrm{F}$ and placebo by COPD severity group. Least squared means and differences in least squared means with corresponding 95\% CIs were presented.

\section{Sensitivity analyses}

In addition to the 3-month analyses, the same statistical methods were applied at 12 months using data from the two 12-month studies. ${ }^{9,12}$ 


\section{Results}

\section{Patient demographics and clinical characteristics}

In total, 1,571 patients who received $\mathrm{B} / \mathrm{F}$ or placebo were identified. Patient flow through the three studies and inclusion in this analysis is shown in Figure 1. Of these, 654 were from the CLIMB study ${ }^{10}$ and received background tiotropium. Six patients with missing $\mathrm{FEV}_{1}$ data and six patients with post-bronchodilator $\mathrm{FEV}_{1}>80 \%$ predicted were excluded from all analyses. The mean age of patients was 63.7 years, and $76.6 \%$ were male. COPD severity was moderate in $377(24.0 \%)$, severe in $962(61.2 \%)$, and very severe in $232(14.8 \%)$ patients, according to GOLD 2016 criteria. ${ }^{6}$ Patient demographics and baseline clinical characteristics, by treatment and COPD severity, are summarized in Table 1. Lung function reversibility (\% predicted) was higher in those with moderate COPD $(10.4 \%-11.3 \%)$ than in those with severe and very severe COPD $(4.1 \%$ and $2.5 \%$, respectively, Table 1). Baseline characteristics for the 917 patients included in the 12-month sensitivity analysis are summarized in Table S1, and the characteristics by study of all the patients are summarized in Table S2.

\section{Exacerbations}

By 3 months, 111 (14.2\%) B/F-treated patients and 196 (25.1\%) patients in the placebo group had experienced at least one exacerbation (Table 2). B/F treatment for 3 months was associated with lower exacerbation rates (moderate COPD: 0.17 [95\% CI 0.12, 0.24]; severe COPD: 0.16 [95\% CI 0.13, 0.21]; very severe COPD: 0.27 [95\% CI $0.19,0.39]$ ]) than placebo (moderate COPD: 0.32 [95\% CI 0.24, 0.42]; severe COPD: 0.38 [95\% CI 0.33, 0.45]; very severe COPD: 0.38 [95\% CI 0.28, 0.53]). Corresponding exacerbation rate reductions with $\mathrm{B} / \mathrm{F}$ compared with placebo were significant for moderate (reduction: $46 \%$; RR: $0.54 ; P=0.005$ ) and severe (reduction: 57\%; RR: $0.43 ; P<0.0001$ ) COPD, although they were not statistically significant in the very severe COPD group (reduction: 29\%; RR: 0.71; $P=0.153$ ) (Figure 2). There were more patients without exacerbations in the $\mathrm{B} / \mathrm{F}$ than placebo group $(85.8 \%$ vs $75.0 \%)$, and the proportion of patients with 1,2 , or $\geq 3$ exacerbations was reduced in B/F-treated patients (Figure S1).

At 12 months, 168 (36.8\%) B/F-treated patients and 195 $(43.0 \%)$ patients in the placebo group had experienced at least one exacerbation (Table 3). B/F was associated with significantly lower exacerbation rates compared with placebo in patients with moderate (reduction: $43 \%$; RR: $0.57 ; P=0.001$ ) and severe (reduction: $38 \%$; RR: $0.62 ; P<0.0001$ ) COPD, although rate reductions were not statistically significant in patients with very severe COPD (reduction: 7\%; RR: 0.93; $P=0.674$, Figure 3).

\section{Dropouts}

Overall, 215 (13.7\%) and 320 (35.2\%) patients dropped out of the combined 3-month and 12-month study populations, respectively. There were fewer dropouts with $\mathrm{B} / \mathrm{F}$ than placebo at 3 months ( $\mathrm{n}=81$ [10.4\%] vs 134 [17.1\%]; Table 2) and 12 months $(\mathrm{n}=129$ [28.3\%] vs 191 [42.1\%]; Table 3). In general, the proportion of dropouts increased with increasing disease severity for both treatments at 3 and 12 months; fewer patients who received $\mathrm{B} / \mathrm{F}$ than placebo dropped out in all three COPD severity groups (Tables 2 and 3).

\section{Lung function, reliever use, and COPD symptoms}

$\mathrm{B} / \mathrm{F}$ was associated with a greater effect on $\mathrm{FEV}_{1}$ than placebo, irrespective of COPD severity (Figure 4A). The change from baseline in $\mathrm{FEV}_{1}(\mathrm{~L})$ after 3 months treatment with $\mathrm{B} / \mathrm{F}$ was 0.16 (95\% CI 0.13, 0.19), 0.10 (95\% CI 0.08, 0.12 ), and 0.09 ( $95 \% \mathrm{CI} 0.06,0.12)$ in moderate, severe, and very severe $\mathrm{COPD}$, respectively. The corresponding values for placebo were $-0.03(95 \% \mathrm{CI}-0.07,0.00),-0.04(95 \%$ CI $-0.06,-0.02)$, and 0.01 (95\% CI $-0.03,0.04)$.

$\mathrm{B} / \mathrm{F}$ also demonstrated a greater effect on morning PEF than placebo (Figure 4B). Changes in morning PEF (L/min) after 3 months treatment with B/F were 15.1 (95\% CI 10.6, 19.5), 7.6 (95\% CI 4.9, 10.2), and 11.1 (95\% CI 6.9, 15.4) in moderate, severe, and very severe COPD, respectively. Corresponding values for placebo were -4.3 (95\% CI -9.0 , $0.3),-6.8(95 \% \mathrm{CI}-9.4,-4.2)$, and 1.1 (95\% CI $-3.2,5.4)$. The improvement with $\mathrm{B} / \mathrm{F}$ versus placebo was greater in patients with moderate and severe COPD than very severe disease.

B/F-treated patients reported significantly less reliever use than patients in the placebo group, irrespective of COPD severity (all $P<0.0001$, Figure 4 C). The change from baseline in total reliever use (inhalations/day) after 3 months treatment with $\mathrm{B} / \mathrm{F}$ versus placebo was $-0.66(95 \%$ CI $-0.94,-0.38),-0.77$ (95\% CI $-0.99,-0.55)$, and -1.50 $(95 \% \mathrm{CI}-2.03,-0.97)$ in moderate, severe, and very severe COPD, respectively. The cohort of patients with very severe COPD, who experienced the greatest improvement relative to placebo, had the highest reliever use at baseline (4.00 and 5.07 inhalations/day in the B/F and placebo arms, respectively).

Compared with placebo, $\mathrm{B} / \mathrm{F}$ was also associated with a statistically significant improvement from baseline in the 

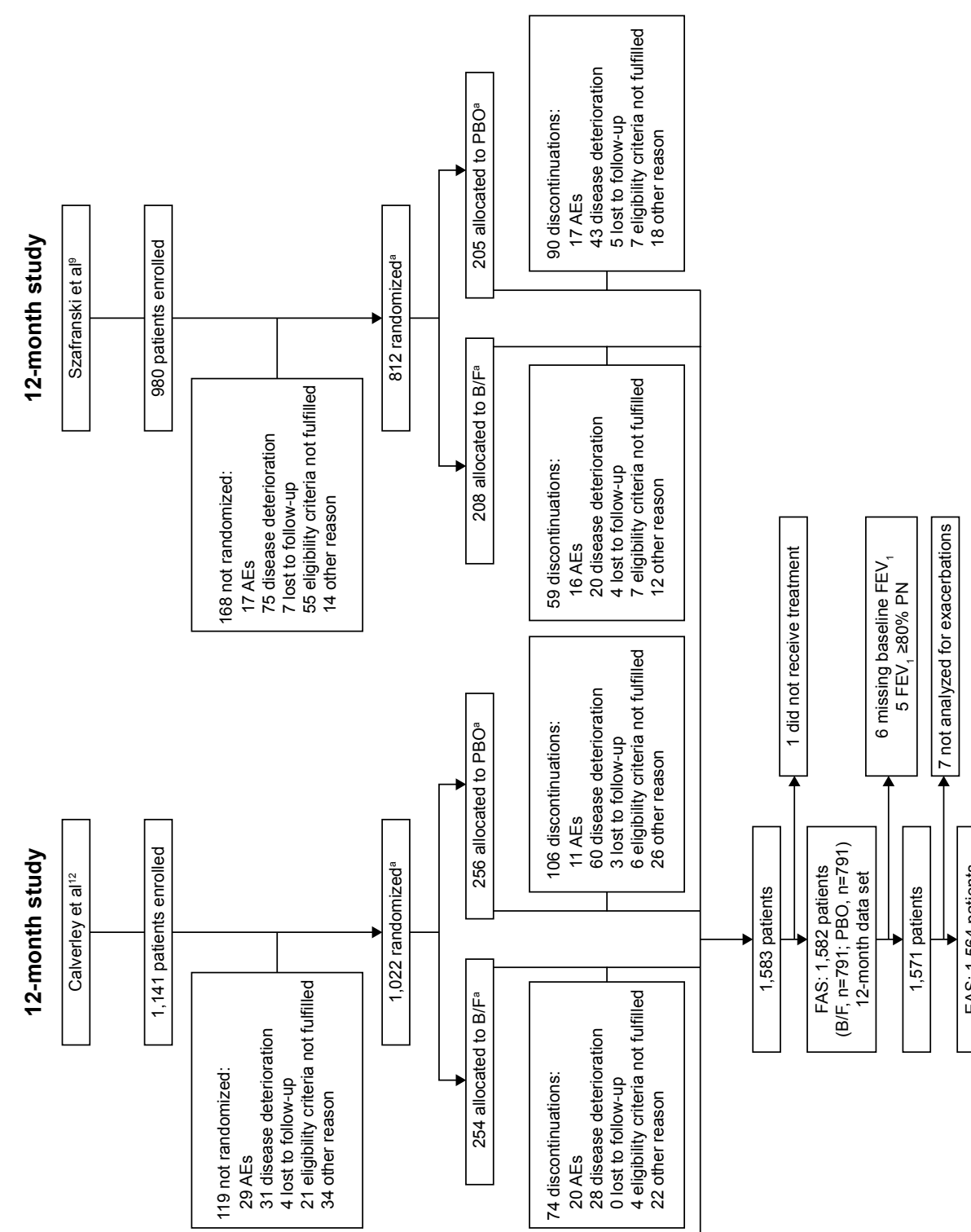

类

ग प

वें

产

范

हु

돈

능

(1)

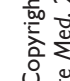

บ

岀

竎
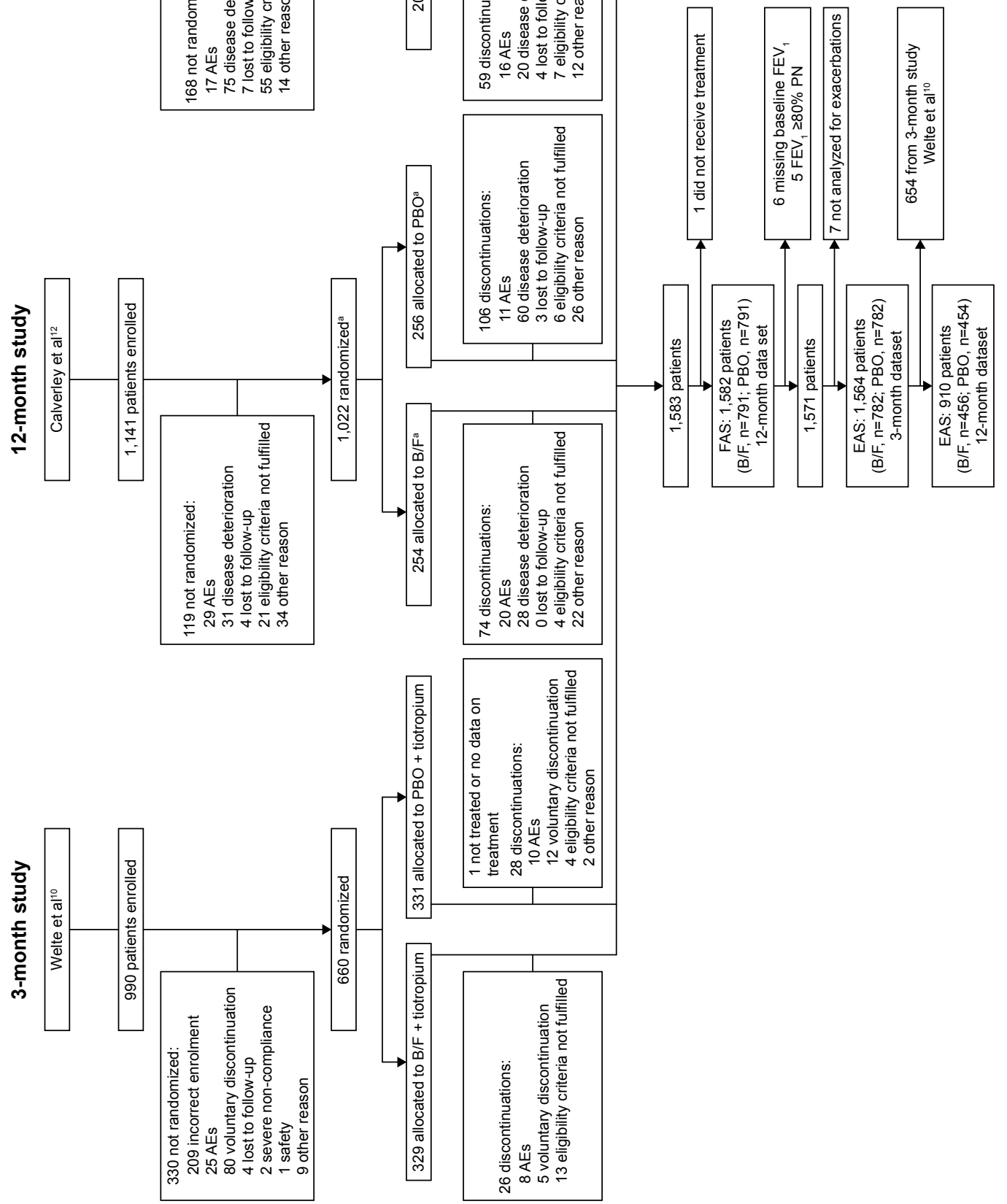

氜

安哭 造

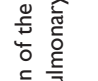

음 $\frac{\varepsilon}{5}$

है

岳 。

莺

就完

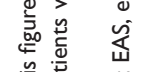

昙兽

पूँ

훈음

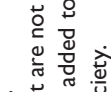

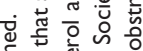

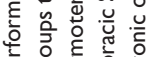

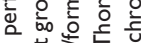

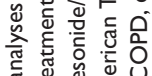

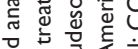

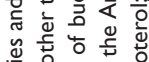

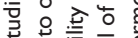

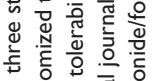

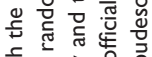

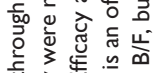

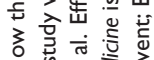

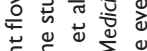

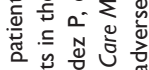

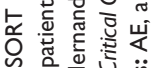

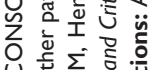

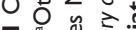

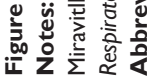




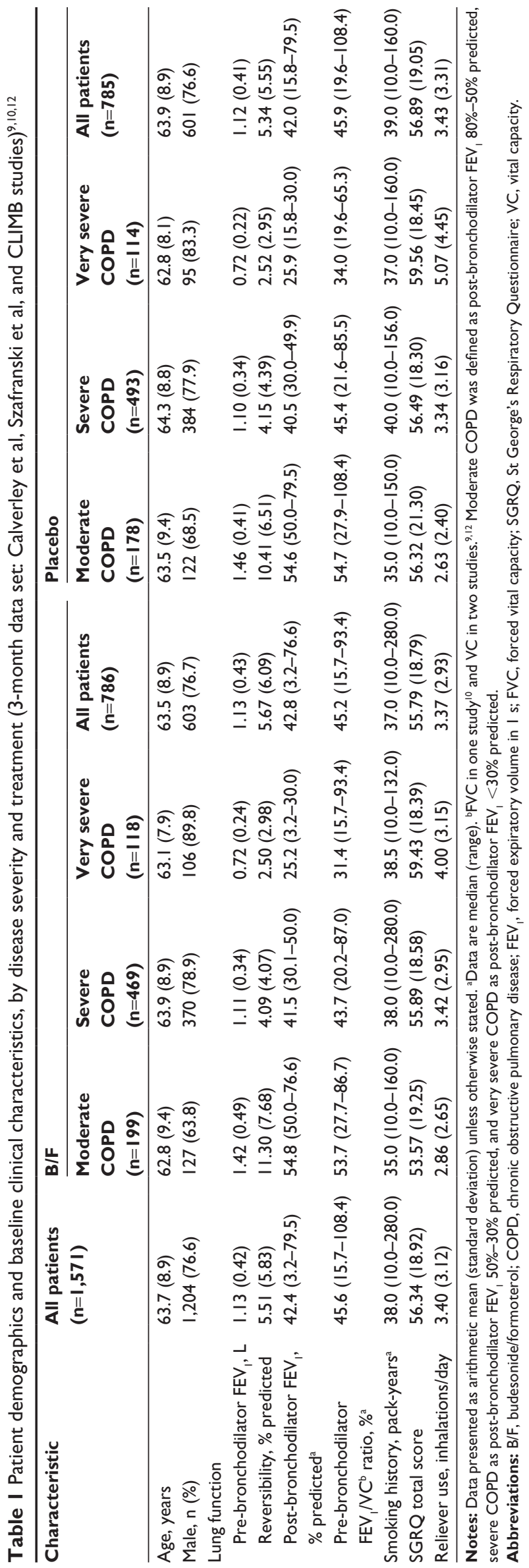

Table 2 Number of patients with at least one exacerbation and dropouts by disease severity in the 3-month data set (Calverley et al, Szafranski et al, and CLIMB studies) (10,12 $^{9}$

\begin{tabular}{|c|c|c|c|c|}
\hline \multirow[t]{2}{*}{ Patients, n (\%) } & \multicolumn{4}{|l|}{$B / F$} \\
\hline & $\begin{array}{l}\text { Moderate } \\
(n=196)\end{array}$ & $\begin{array}{l}\text { Severe } \\
(n=469)\end{array}$ & $\begin{array}{l}\text { Very severe } \\
(n=|| 7)\end{array}$ & $\begin{array}{l}\text { All } \\
(n=782)\end{array}$ \\
\hline COPD exacerbation & $24(12.2)$ & $60(12.8)$ & $27(23.1)$ & $111(14.2)$ \\
\hline \multirow[t]{3}{*}{ Dropout } & $20(10.2)$ & $47(10.0)$ & $14(12.0)$ & $81(10.4)$ \\
\hline & \multicolumn{4}{|l|}{ Placebo } \\
\hline & $\begin{array}{l}\text { Moderate } \\
(n=\mid 78)\end{array}$ & $\begin{array}{l}\text { Severe } \\
(n=492)\end{array}$ & $\begin{array}{l}\text { Very severe } \\
(n=I \mid 2)\end{array}$ & $\begin{array}{l}\text { All } \\
(n=782)\end{array}$ \\
\hline COPD exacerbation & 44 (24.7) & $122(24.8)$ & $30(26.8)$ & $196(25.1)$ \\
\hline Dropout & $28(15.7)$ & $81(16.5)$ & $25(22.3)$ & $134(17.1)$ \\
\hline
\end{tabular}

Notes: ${ }^{2}$ The 3-month data set includes 3-month data from the two 12-month studies ${ }^{9,12}$ as well as that from the 3 -month study. ${ }^{10}$ ITT population includes only patients analyzed for exacerbations $(n=I, 564)$. Moderate COPD was defined as postbronchodilator $\mathrm{FEV}, 80 \%-50 \%$ predicted, severe $\mathrm{COPD}$ as post-bronchodilator $\mathrm{FEV}$, $50 \%-30 \%$ predicted, and very severe COPD as post-bronchodilator $\mathrm{FEV},<30 \%$ predicted.

Abbreviations: $\mathrm{B} / \mathrm{F}$, budesonide/formoterol; COPD, chronic obstructive pulmonary disease; $\mathrm{FEV}_{1}$, forced expiratory volume in I $\mathrm{s}$.

total symptom score, irrespective of COPD severity (all $P<0.0001$, Figure 4D). The change from baseline in total symptom score after 3 months treatment with $\mathrm{B} / \mathrm{F}$ was -1.23 (95\% CI $-1.46,-0.99),-0.57$ (95\% CI $-0.73,-0.41)$, and $-0.92(95 \% \mathrm{CI}-1.28,-0.56)$ in moderate, severe, and very severe $\mathrm{COPD}$, respectively. The corresponding values for placebo were $-0.26(95 \% \mathrm{CI}-0.51,-0.01),-0.04(95 \%$ CI $-0.19,0.11)$, and $0.34(95 \% \mathrm{CI}-0.03,0.70)$.

\section{Safety}

Pooled analysis of adverse events (AEs) and serious AEs across the three studies found no difference between $\mathrm{B} / \mathrm{F}$ and placebo after 3 and 12 months treatment, while the number of discontinuations due to an $\mathrm{AE}$ was lower in $\mathrm{B} / \mathrm{F}$-treated than placebo-treated patients at both 3 months (5.8\% vs $11.5 \%)$ and 12 months (17.5\% vs $25.8 \%$ ) (Tables S3 and S4, respectively). Ten patients in each treatment group (2.2\%) had a fatal AE. Pooled analysis of the most frequently reported AEs in each treatment group after 3 and 12 months treatment are summarized in Tables S5 and S6. At 3 months, the most frequently reported AEs were COPD (7.1\% B/F vs $13.0 \%$ placebo), nasopharyngitis ( $3.8 \%$ vs $3.3 \%$ ), and headache $(1.5 \%$ vs $0.9 \%)$.

\section{Discussion}

Previous analyses have shown that ICS/LABA combinations produce improvements in a range of clinical outcomes versus placebo, including prolonged time to first exacerbation, improved lung function, and improved health-related quality of life. ${ }^{9}{ }^{12-14}$ These improved outcomes are greater with ICS/LABA combinations than with either agent alone 

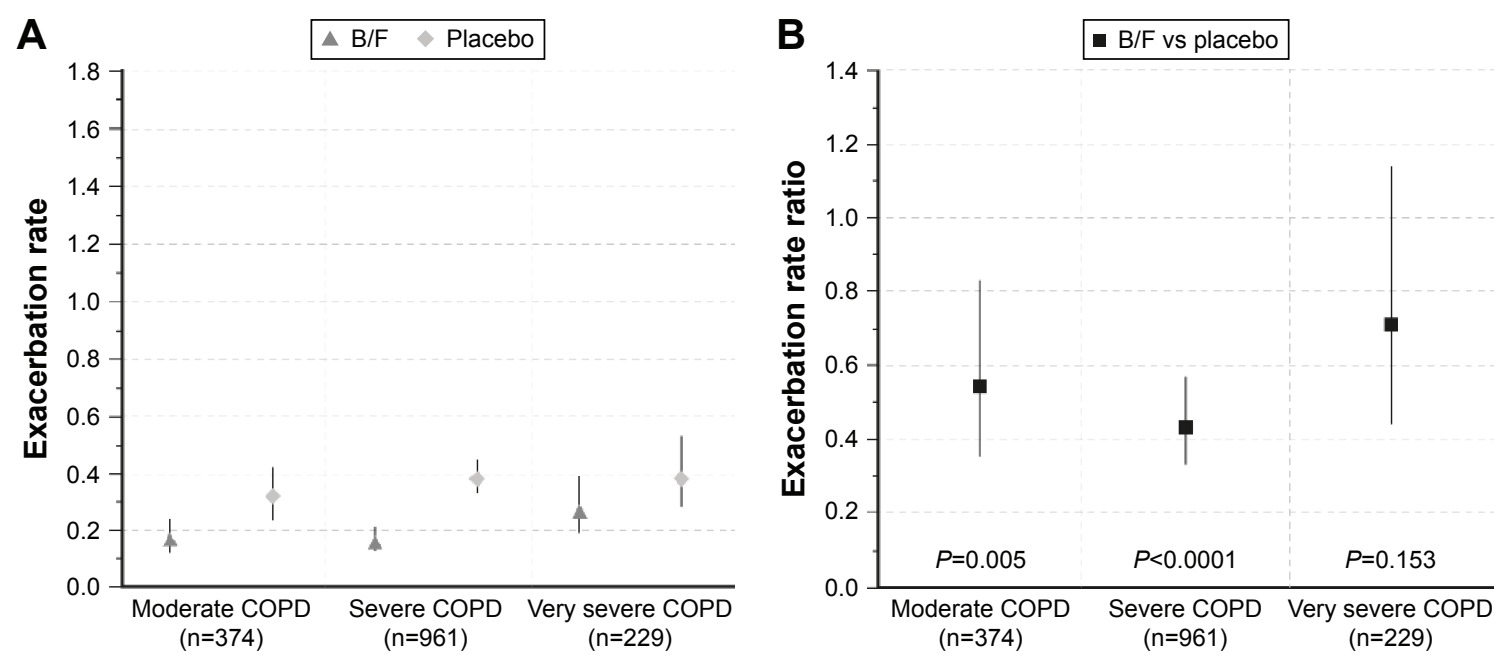

Figure 2 (A) 3-month exacerbation rates in patients with moderate, severe, and very severe COPD receiving B/F or placebo; and (B) 3-month exacerbation rate ratios between $\mathrm{B} / \mathrm{F}$ and placebo, by disease severity. Vertical lines represent $95 \%$ confidence intervals. Moderate COPD was defined as post-bronchodilator $\mathrm{FEV}$, $80 \%-50 \%$ predicted, severe COPD as post-bronchodilator FEV, 50\%-30\% predicted, and very severe COPD as post-bronchodilator FEV $<30 \%$ predicted, according to GOLD 2016 criteria (3-month data set; Calverley et al, Szafranski et al, and CLIMB studies). , $10,12^{2}$

Abbreviations: $\mathrm{B} / \mathrm{F}$, budesonide/formoterol; COPD, chronic obstructive pulmonary disease; $\mathrm{FEV}_{1}$, forced expiratory volume in I s.

at 12 months. ICS/LABA combinations can be used either as a primary treatment ${ }^{9,12-15}$ or in addition to therapy with a long-acting antimuscarinic agent in the management of severe COPD. ${ }^{10}$ However, the early effects (within the first 3 months) of ICS/LABA following treatment initiation are less well understood. This study investigated the early effects of this combination compared with placebo when used either alone $^{9,12}$ or in addition to tiotropium ${ }^{10}$ in different COPD severities. Of clinical relevance, the beneficial effects of $\mathrm{B} / \mathrm{F}$ compared with placebo on exacerbations were evident within 3 months of treatment and were paralleled by improved lung function, reduced need for reliever use, and fewer symptoms

Table 3 Number of patients with at least one exacerbation and dropouts by disease severity in the 12-month data set (12-month data set; Calverley et al, and Szafranski et al studies only) ${ }^{9,12}$

\begin{tabular}{|c|c|c|c|c|}
\hline \multirow[t]{2}{*}{ Patients, n (\%) } & \multicolumn{4}{|l|}{$B / F$} \\
\hline & $\begin{array}{l}\text { Moderate } \\
(n=106)\end{array}$ & $\begin{array}{l}\text { Severe } \\
(n=266)\end{array}$ & $\begin{array}{l}\text { Very severe } \\
(n=84)\end{array}$ & $\begin{array}{l}\text { All } \\
(n=456)\end{array}$ \\
\hline COPD exacerbation & $30(28.3)$ & $96(36.1)$ & $42(50.0)$ & 168 (36.8) \\
\hline \multirow[t]{3}{*}{ Dropout } & $22(20.8)$ & $80(30.1)$ & $27(32.1)$ & $129(28.3)$ \\
\hline & \multicolumn{4}{|l|}{ Placebo } \\
\hline & $\begin{array}{l}\text { Moderate } \\
(n=108)\end{array}$ & $\begin{array}{l}\text { Severe } \\
(n=275)\end{array}$ & $\begin{array}{l}\text { Very severe } \\
(n=71)\end{array}$ & $\begin{array}{l}\text { All } \\
(n=454)\end{array}$ \\
\hline COPD exacerbation & $43(39.8)$ & $121(44.0)$ & 31 (43.7) & $195(43.0)$ \\
\hline Dropout & $4 \mid(38.0)$ & II 5 (4I.8) & $35(49.3)$ & 191 (42.I) \\
\hline
\end{tabular}

Notes: ${ }^{2}$ The 12-month data set includes data from the two 12-month studies.9.12 ITT population includes only patients analyzed for exacerbations $(n=9 \mid 0)$. Moderate COPD was defined as post-bronchodilator $\mathrm{FEV}, 80 \%-50 \%$ predicted, severe COPD as post-bronchodilator $\mathrm{FEV}, 50 \%-30 \%$ predicted, and very severe COPD as postbronchodilator $\mathrm{FEV},<30 \%$ predicted.

Abbreviations: B/F, budesonide/formoterol; COPD, chronic obstructive pulmonary disease; $\mathrm{FEV}_{1}$, forced expiratory volume in I s. compared with placebo, irrespective of the severity of COPD. The beneficial effects of $\mathrm{B} / \mathrm{F}$ on exacerbation rate, lung function, symptoms, and health-related quality of life have been reported previously in comparison with both budesonide and formoterol alone. ${ }^{9,12}$

In the three studies included in the analysis, ${ }^{9,10,12}$ exacerbation rate was assessed in patients with COPD who would fall within grades B, C, and D of the new GOLD classification. ${ }^{6}$ Conventionally, exacerbations are defined by health care utilization and are reported over 1 year, which increases the number of events and, hence, the statistical power to detect any difference between treatments. This analysis focused on the first 3 months of treatment, thus reducing the total number of exacerbation events. Despite this, one-quarter of those randomized to placebo reported at least one event, and this was significantly more than that seen with combination treatment. Although more patients dropped out in the placebo arm than in the active treatment group, our analyses still had sufficient power to detect treatment-related differences, not only for exacerbation rates, but in lung function improvement, reliever use, and self-reported symptoms.

A consistent reduction in the exacerbation rate over the first 3 months of treatment was observed in patients with spirometrically defined moderate or severe disease. Although there were proportionally more exacerbations in patients with very severe disease, more patients in this group dropped out, which may explain the lack of treatment effect observed. The effect of differential withdrawal on treatment effect has been described previously ${ }^{16}$ and merits further study. 
A

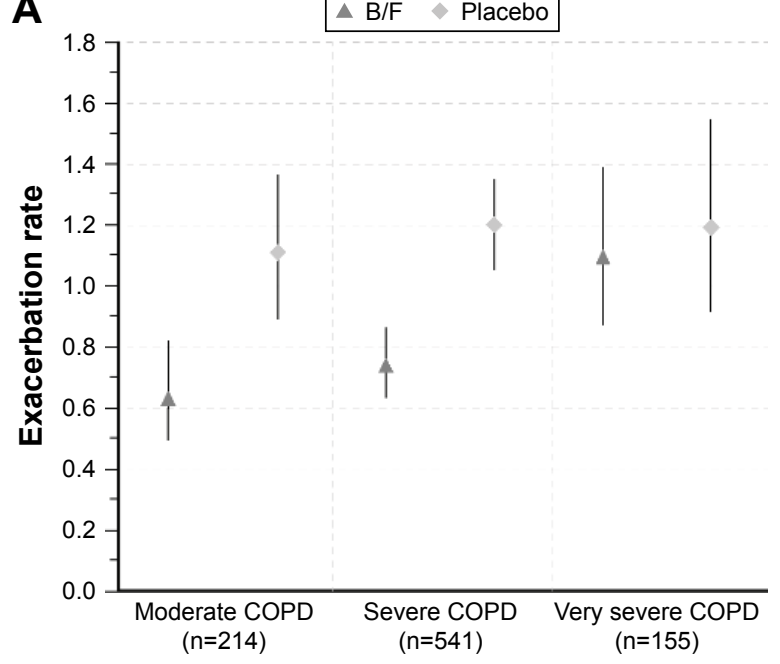

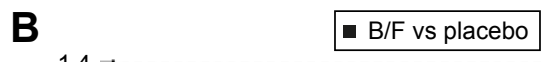

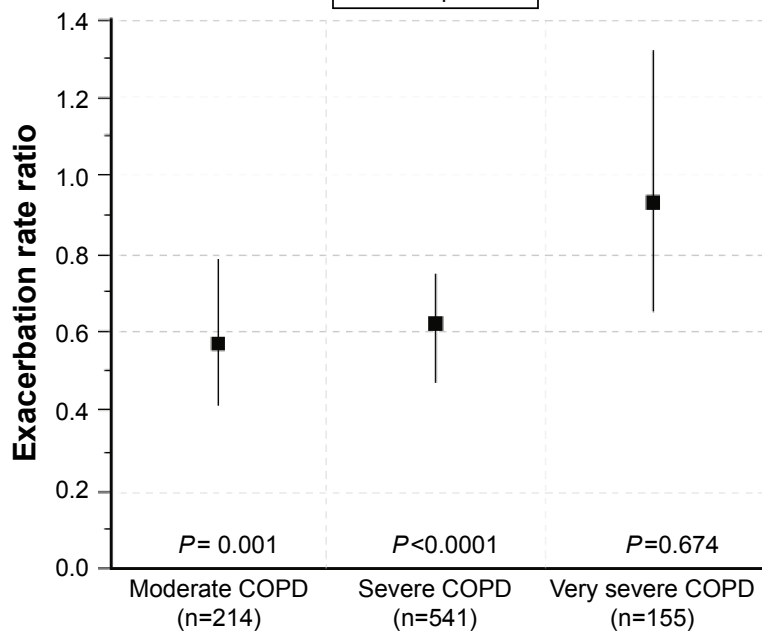

Figure 3 (A) Annual exacerbation rates in patients with moderate, severe, and very severe COPD receiving B/F or placebo and (B) annual exacerbation rate ratios between $\mathrm{B} / \mathrm{F}$ and placebo, by disease severity. Vertical lines represent $95 \%$ confidence intervals. Moderate COPD was defined as FEV, $80 \%-50 \%$ predicted, severe COPD as FEV, 50\%$30 \%$ predicted, and very severe COPD as FEV $<30 \%$ predicted, according to GOLD 2016 criteria (I2-month data set; Calverley et al and Szafranski et al studies only) ${ }^{9,12}$ Abbreviations: B/F, budesonide/formoterol; COPD, chronic obstructive pulmonary disease; $\mathrm{FEV}_{1}$, forced expiratory volume in I s.

A

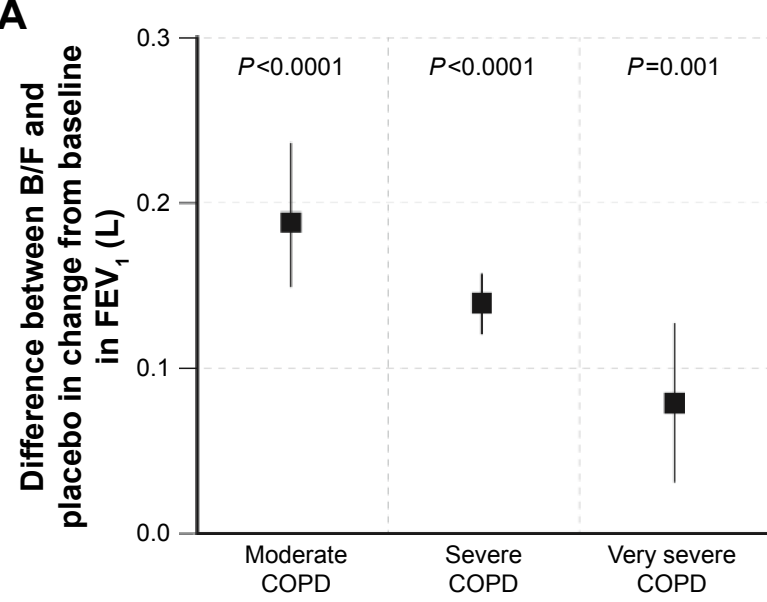

C

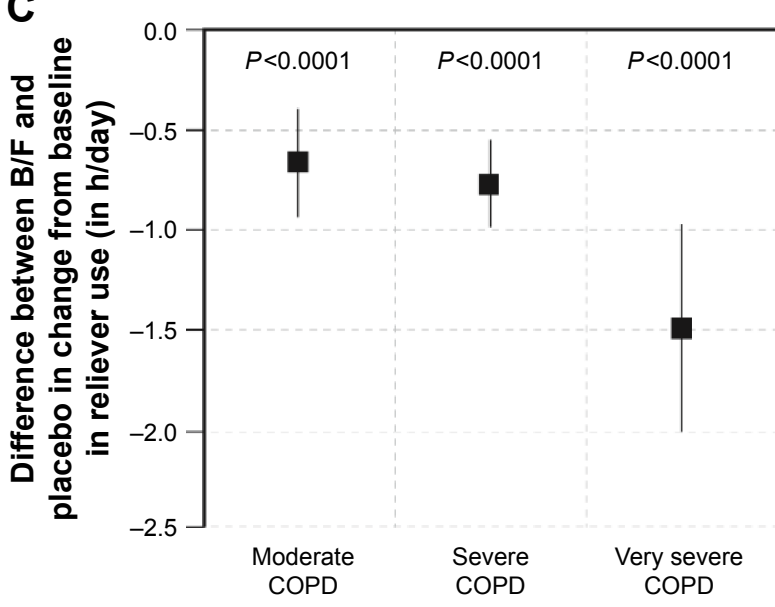

B

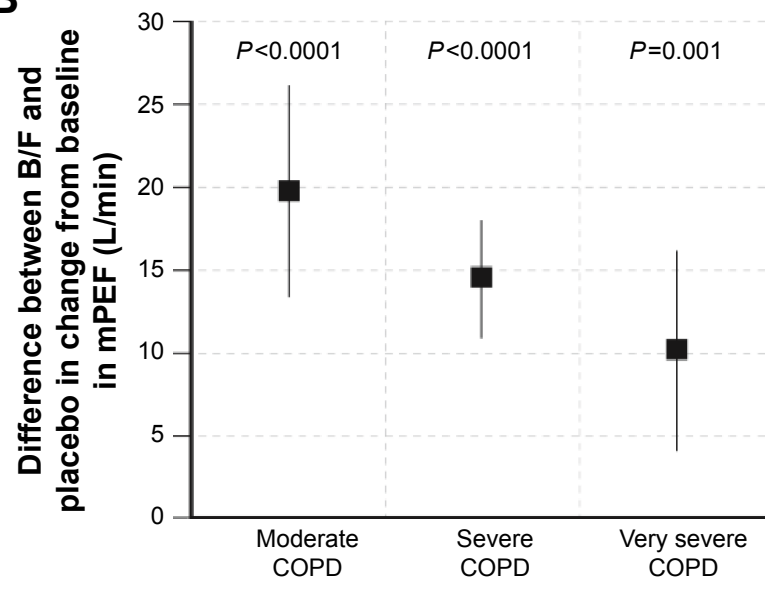

D

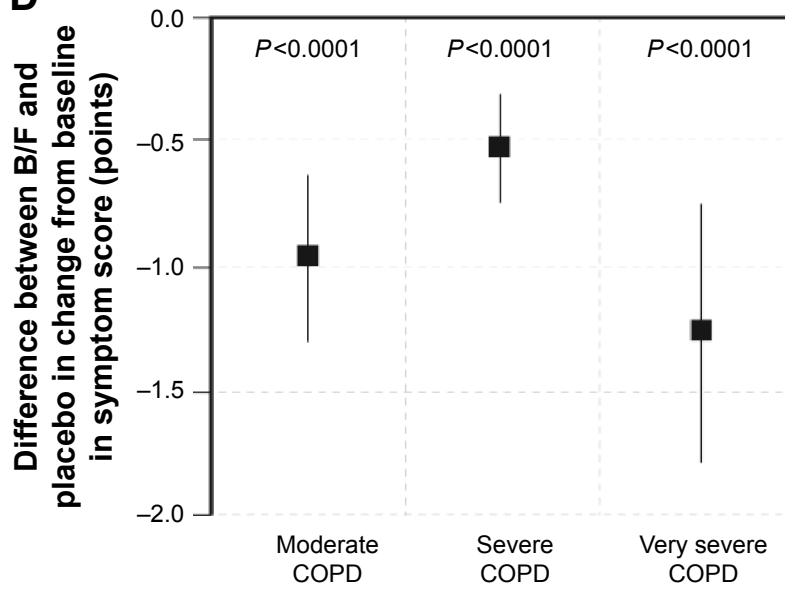

Figure 4 Difference in the mean change from baseline in $(\mathbf{A}) \mathrm{FEV}_{j} ;(\mathbf{B})$ morning PEF; (C) daily reliever use; and (D) symptom score between $\mathrm{B} / \mathrm{F}$ and placebo, by disease severity. Vertical lines represent $95 \%$ confidence intervals. Moderate COPD was defined as FEV $80 \%-50 \%$ predicted, severe COPD as FEV $50 \%-30 \%$ predicted, and very severe COPD as $\mathrm{FEV}_{1}<30 \%$ predicted, according to GOLD 2016 criteria (3-month data set; Calverley et al, Szafranski et al, and CLIMB studies). ${ }^{9}, 10,12$

Abbreviations: B/F, budesonide/formoterol; COPD, chronic obstructive pulmonary disease; FEV ${ }_{1}$, forced expiratory volume in I s; inh, inhalations; mPEF, morning peak expiratory flow rate. 
The analyses were well powered to detect the effects of treatment on spirometry, confirming 1-year spirometry findings in the studied trials ${ }^{9,10,12}$ and agreeing with results of other studies $;{ }^{13-15}$ in addition, the analyses showed a treatment effect 3 months after randomization. These data were supported by the PEF recordings from the daily diary cards, which confirmed earlier reports of a treatment effect being evident within 1 week of randomization. ${ }^{9}$ Statistically significant, although generally smaller, changes in lung function were seen as baseline $\mathrm{FEV}_{1}$ worsened. This accords with observations of the acute bronchodilator effects in COPD, with smaller relative and absolute increases in $\mathrm{FEV}_{1}$ as GOLD severity increases. ${ }^{17}$ This smaller response is likely to reflect the increased prevalence of tidal expiratory flow limitation in more severe $\mathrm{COPD}^{18}$ and points toward the importance of lung volume change, rather than spirometry in these circumstances. Although the absolute changes in lung function in our data were small, the improvements in terms of rescue medication and their relationship to improved symptom scores were, if anything, greater in patients with worse baseline spirometry. This is important as we have shown that increased use of reliever medication is a marker for exacerbation risk. ${ }^{19}$ The presence of a statistically significant change in all these outcomes suggests that, for a significant number of individuals, combination therapy offers worthwhile improvements within 3 months of commencement across a range of clinically relevant measures.

This post hoc analysis has focused on changes in efficacy measures at 3 months after initiation of treatment. The effects of combination therapy across a range of safety and tolerability measures have been previously reported in the original publications. ${ }^{910,12}$ In this pooled safety analysis, the observed rates of AEs, serious AEs, and deaths due to AEs were similar in the $\mathrm{B} / \mathrm{F}$ group to that observed in the placebo group, consistent with the original individual studies, ${ }^{9,10,12}$ while discontinuations due to AEs occurred less frequently in patients treated with $\mathrm{B} / \mathrm{F}$ than those receiving placebo. Prior to the analysis, it was determined that when separated out and analyzed by disease severity, the number of individual types of events such as pneumonia would be too small for meaningful interpretation.

This study data have strengths and limitations. The study reports data from a large number of patients, covering a range of spirometric severity, and includes comparisons with placebo. Reductions in 3-month exacerbation rates have previously been reported in prospective studies and were $62 \%$ for $\mathrm{B} / \mathrm{F}$ plus tiotropium versus tiotropium plus placebo ${ }^{10}$ and $36 \%$ for $\mathrm{B} / \mathrm{F}$ versus formoterol. ${ }^{20}$ Although the current analysis was post hoc in terms of the primary study outcomes, it adds to the literature, as investigating the effect of an ICS/LABA combination at 3 months in different disease severities is novel. In one study that had been included in the analysis, all patients used tiotropium as a maintenance bronchodilator, and the lower exacerbation rates reported here at 3 months may reflect this. ${ }^{10}$ However, the behavior of patients in this study did not differ from those in the other two studies in which the baseline exacerbation rate was higher in the placebo arm..$^{9,12}$ In addition, data were not available on prior exacerbation history or Medical Research Council breathlessness score to use in the analysis by the current GOLD grouping.

This study considered only exacerbations that led to the use of oral corticosteroids (alone or in combination with antibiotics) and/or hospitalization or emergency room visits, a definition currently supported by the GOLD initiative and others. This could, however, identify a more steroid-responsive exacerbation type. Pooled diary card symptom scores could identify treatment effects ${ }^{21}$ but unlike more recent tools, ${ }^{22,23}$ they were not validated to identify exacerbations that did not require medical treatment. If we had been able to use this approach, it is likely that the number of events being identified would have been greater. Evidence from other studies suggests that the trend of such events would have been similar to those where patients had sought increases in treatment, ${ }^{24}$ and hence, these additional episodes might have allowed to draw the same conclusion with fewer patients.

\section{Limitations}

Other limitations include the number of patients who dropped out from the study, by both 3 and 12 months. This may have affected the accuracy of the results, including exacerbation rates. High dropout rates can confound the interpretation of randomized controlled trials and can be a common feature in trials involving patients with COPD, with some analyses reporting $27 \%-53 \%$ dropout. ${ }^{25}$ In addition, the moderate group in our analysis had airway reversibility of $10 \%-11 \%$ (\% predicted). It is now recognized that COPD patients with moderate airflow obstruction show a greater absolute change in $\mathrm{FEV}_{1}$ post-bronchodilator than that seen in more severe disease. ${ }^{26}$ This contributes to the greater degree of reversibility reported in analyses of moderate patients in clinical trials similar to this study. The entry criteria for the three studies included in this analysis are consistent with those of other clinical trials in the area and did not select patients on the basis of known reversibility to bronchodilators.

These data have implications for the use and evaluation of treatment in COPD. It was found that a measurable effect on COPD exacerbations (defined by symptoms necessitating 
the addition of, or treatment with, oral or systemic corticosteroids) occurred within 3 months of randomization to the ICS/LABA combination in COPD patients who had experienced at least one exacerbation in the past year. This positive effect on exacerbation frequencies was paralleled by improved lung function, lower use of reliever medication, and fewer symptoms. Whether these changes in objective patient-reported outcomes can be used to predict a further course of events remains to be established at an individual patient level. However, they should reassure clinicians that treatment is effective across a range of endpoints, including exacerbation prevention, soon after initiation.

\section{Conclusions}

In conclusion, data from this study show that treatment with an ICS/LABA combination has important clinical impact irrespective of disease severity; these effects are evident within 3 months after the initiation of treatment.

\section{Acknowledgments}

The authors would like to thank Thomas Similowski and Ian Naya for their contributions to this manuscript. We also thank Katharine Williams and Ash Dunne of inScience Communications, Springer Healthcare, who provided medical writing support funded by AstraZeneca. The sponsor (AstraZeneca) funded this analysis and was involved in the analysis, design, and interpretation of the data, always in conjunction with the authors. The University of Groningen has received money for research by unrestricted educational grants from AstraZeneca and Chiesi. AstraZeneca, Boehringer Ingelheim, Chiesi, GlaxoSmithKline, and Nycomed have provided support for travel to meetings.

The current address of Anders Persson is Centre of Registers, Västra Götaland, Sweden.

\section{Author contributions}

PMC, GE, CRJ, ARA, BJM, AP, MF, and DSP all contributed to the conception, writing, and revision of the manuscript, and approved the final version for submission. AP was responsible for statistical analyses. All authors contributed toward data analysis, drafting and revising the paper and agree to be accountable for all aspects of the work.

\section{Disclosure}

PMC is a board member for Boehringer Ingelheim, the Department of Health Respiratory Programme Board, GlaxoSmithKline, and Nycomed. He has been a consultant for Novartis and provided expert testimony for Forest. PMC has received honoraria for advising on the conduct and analysis of clinical trial data from AstraZeneca, Boehringer Ingelheim, GlaxoSmithKline, Novartis, and Nycomed. He has also spoken at meetings supported by these companies. Support for travel to meetings has been provided by AstraZeneca.

GE is an ex-employee of AstraZeneca. He has consulted for Airsonett, ALK and Novartis, participated in advisory board meeting with Almirall, and is a member of the Medicon Village Inhalation Centre (MVIC).

CRJ is an advisory board member for AstraZeneca, Boehringer Ingelheim, GlaxoSmithKline, and Novartis, and a consultant for AstraZeneca, GlaxoSmithKline, Pieris, and Chiesi. Educational presentations have been developed for AstraZeneca, Boehringer Ingelheim, GlaxoSmithKline, and Novartis, with honoraria paid to CRJ or her institution. Lectures have been presented on behalf of AstraZeneca, Boehringer Ingelheim, GlaxoSmithKline, and Novartis. Support for travel to meetings has been provided by AstraZeneca and Boehringer Ingelheim.

ARA is a consultant and speaker for AstraZeneca, Bayer Pharma, Boehringer Ingelheim, Dey Pharma, GlaxoSmithKline, and Pfizer, and has received honoraria from these companies. Educational presentations have been developed for AstraZeneca, Bayer Pharma, Boehringer Ingelheim, Dey Pharma, GSK, and Pfizer. The University of Texas Health Science Center at San Antonio has received money for research to perform clinical trials. Support for travel to meetings has also been provided by AstraZeneca.

BJM is an advisory board member for Aerocrine, AstraZeneca, Forest, Boehringer Ingelheim, CSL Bering, Forest, Novartis, and Theravance and a consultant for Astellas, Forest, and Chiesi. Clinical trial data have been reviewed for Spiration, with grants received and controlled by National Jewish Health from AstraZeneca, Boehringer Ingelheim, GlaxoSmithKline, Forest, MedImmune, Nabi, National Institutes of Health, Pfizer, and Sunovian. Lectures have been presented on behalf of Boehringer Ingelheim and GlaxoSmithKline. Educational presentations and programs have been developed (Carden Jennings, Cleveland Clinic, Consensus Medical, Foundation for Improving Patient Outcomes, Hybrid Communications, Integrity, Intellisphere, Medscape, National Jewish Health, Projects in Knowledge, SPIRE, Synapse, and WebMD). Royalties have been received from Up-To-Date. BJM has been a speaker for educational programs at Abbott, the American Academy of Family Practice, the American College of Chest Physicians, and the American Thoracic Society. Support for travel to meetings has also been provided by AstraZeneca.

AP and MF are employees of AstraZeneca and own stocks within the company. 
The University of Groningen has received honoraria for DSP advising on the conduct and analysis of clinical trial data from AstraZeneca, Nycomed, and Teva, as well as for lectures at meetings supported by AstraZeneca, Chiesi, GlaxoSmithKline, Nycomed, and Teva.

\section{References}

1. Murray C, Richards M, Newton J, et al. UK health performance: findings of the Global Burden of Disease Study 2010. Lancet. 2013;381(9871): 997-1020.

2. Yang G, Wang Y, Zeng Y, et al. Rapid health transition in China, 1990-2010: findings from the Global Burden of Disease Study 2010. Lancet. 2013;381(9882):1987-2015.

3. Calverley P, Anderson J, Celli B, et al. Salmeterol and fluticasone propionate and survival in chronic obstructive pulmonary disease. $N$ Engl J Med. 2007;356(8):775-789.

4. Tashkin D, Celli B, Senn S, et al. A 4-year trial of tiotropium in chronic obstructive pulmonary disease. $N$ Engl J Med. 2008;359(15): 1543-1554.

5. De Soyza A, Calverley PMA. Large trials, new knowledge: the changing face of COPD management. Eur Respir J. 2015;45(6):1692-1703.

6. Global Initiative for Chronic Obstructive Lung Disease (GOLD). From the Global Strategy for the Diagnosis, Management, and Prevention of COPD, Global Initiative for Chronic Obstructive Lung Disease (GOLD). Updated 2016. Available from: http://www.goldcopd.org/2016. Accessed January 2016.

7. Wise RA, Anzueto A, Cotton D, et al. Tiotropium Respimat inhaler and the risk of death in COPD. N Engl JMed. 2013;369(16):1491-1501.

8. Vestbo J, Pauwels R, Anderson J, Jones P, Calverley P; TRISTSAN Group. Early onset of effect of salmeterol and fluticasone propionate in chronic obstructive pulmonary disease. Thorax. 2005;60(4):301-304.

9. Szafranski W, Cukier A, Ramirez A, et al. Efficacy and safety of budesonide/formoterol in the management of chronic obstructive pulmonary disease. Eur Respir J. 2003;21(1):74-81.

10. Welte T, Miravitlles M, Hernandez P, et al. Efficacy and tolerability of budesonide/formoterol added to tiotropium in patients with chronic obstructive pulmonary disease. Am J Respir Crit Care Med. 2009;180(8): 741-750.

11. Jenkins CR, Jones PW, Calverley PM, et al. Efficacy of salmeterol/ fluticasone propionate by GOLD stage of chronic obstructive pulmonary disease: analysis from the randomised, placebo-controlled TORCH study. Respir Res. 2009;10:59.

12. Calverley PM, Boonsawat W, Cseke Z, Zhong N, Peterson S, Olsson H. Maintenance therapy with budesonide and formoterol in chronic obstructive pulmonary disease. Eur RespirJ. 2003;22(6):912-919.

13. Rennard S, Tashkin D, McElhattan J, et al. Efficacy and tolerability of budesonide/formoterol in one hydrofluoroalkane pressurized metereddose inhaler in patients with chronic obstructive pulmonary disease: results from a 1-year randomized controlled clinical trial. Drugs. 2009; 69(5):549-565.
14. Tashkin D, Rennard S, Martin P, et al. Efficacy and safety of budesonide and formoterol in one pressurized metered-dose inhaler in patients with moderate to very severe chronic obstructive pulmonary disease: results of a 6-month randomized clinical trial. Drugs. 2008;68(14): $1975-2000$

15. Sharafkhaneh A, Southard J, Goldman M, Uryniak T, Martin U. Effect of budesonide/formoterol pMDI on COPD exacerbations: a doubleblind, randomized study. Respir Med. 2012;106(2):257-268.

16. Calverley PM, Spencer S, Willits L, Burge PS, Jones PW. Withdrawal from treatment as an outcome in the ISOLDE study of COPD. Chest. 2003;124(4):1350-1356.

17. Albert P, Agusti A, Edwards L, et al. Bronchodilator responsiveness as a phenotypic characteristic of established chronic obstructive pulmonary disease. Thorax. 2012;67(8):701-708.

18. Dellacà R, Pompilio P, Walker P, Duffy N, Pedotti A, Calverley P. Effect of bronchodilation on expiratory flow limitation and resting lung mechanics in COPD. Eur Respir J. 2009;33(6):1329-1337.

19. Jenkins CR, Postma DS, Anzueto AR, et al. Reliever salbutamol use as a measure of exacerbation risk in chronic obstructive pulmonary disease. BMC Pulm Med. 2015;15:97.

20. Fukuchi Y, Samoro R, Fassakhov R, et al. Budesonide/formoterol via Turbuhaler(R) versus formoterol via Turbuhaler(R) in patients with moderate to severe chronic obstructive pulmonary disease: phase III multinational study results. Respirology. 2013;18(5):866-873.

21. Calverley P, Pauwels Dagger R, Lofdahl CG, et al. Relationship between respiratory symptoms and medical treatment in exacerbations of COPD. Eur Respir J. 2005;26(3):406-413.

22. Leidy N, Wilcox T, Jones P, et al. Standardizing measurement of chronic obstructive pulmonary disease exacerbations. Reliability and validity of a patient-reported diary. Am J Respir Crit Care Med. 2011; 183(3):323-329.

23. Jones P, Brusselle G, Dal Negro R, et al. Properties of the COPD assessment test in a cross-sectional European study. Eur Respir J. 2011; 38(1):29-35.

24. Wedzicha J, Decramer M, Ficker J, et al. Analysis of chronic obstructive pulmonary disease exacerbations with the dual bronchodilator QVA149 compared with glycopyrronium and tiotropium (SPARK): a randomised, double-blind, parallel-group study. Lancet Respir Med. 2013;1(3):199-209.

25. Wilt TJ, Niewoehner D, MacDonald R, Kane RL. Management of stable chronic obstructive pulmonary disease: a systematic review for a clinical practice guideline. Ann Intern Med. 2007;147(9):639-653.

26. Calverley PM, Albert P, Walker PP. Bronchodilator reversibility in chronic obstructive pulmonary disease: use and limitations. Lancet. 2013;1(7):564-573. 


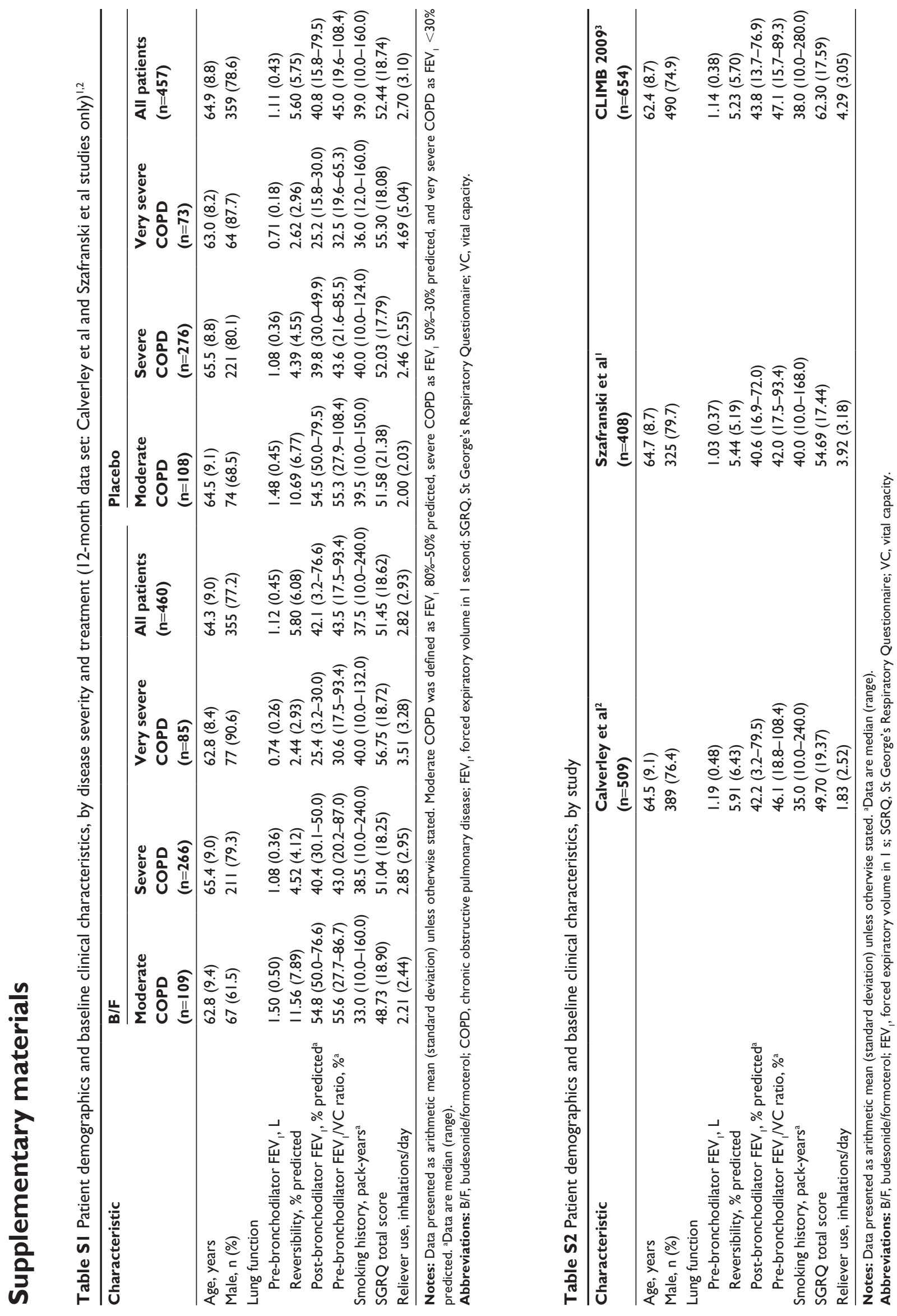




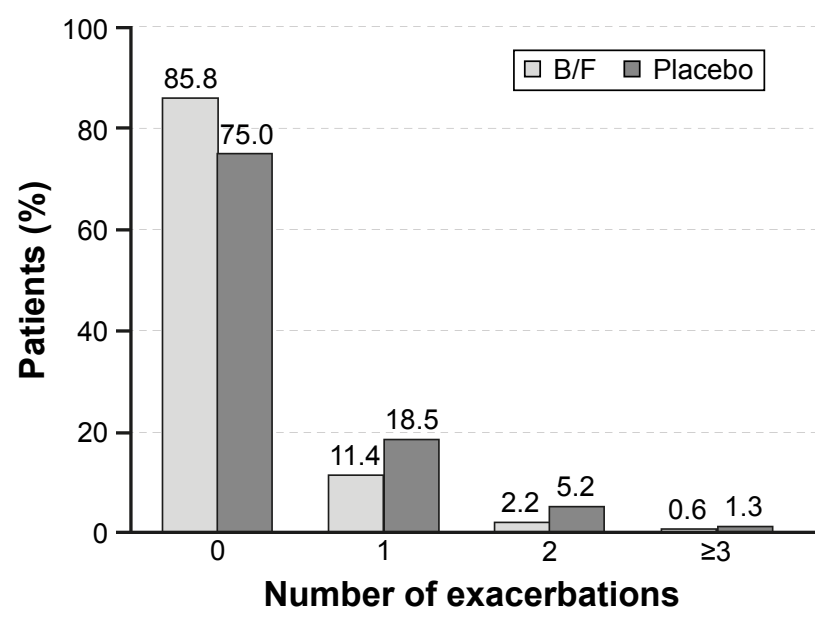

Figure SI Proportion of patients with moderate-to-very-severe COPD who received B/F or placebo and who had zero, I, 2, or $\geq 3$ exacerbations over the 3-month study period.

Abbreviations: B/F, budesonide/formoterol; COPD, chronic obstructive pulmonary disease.

Table S3 Number (\%) of patients who had an adverse event (AE) in any category in the 3-month budesonide/formoterol vs placebo pool (Welte et al, Calverley et al, and Szafranski et al studies) ${ }^{1,2,4}$

\begin{tabular}{lll}
\hline Category of AE & $\begin{array}{l}\text { Budesonide/formoterol } \\
(\mathbf{n = 7 9 1 )}\end{array}$ & $\begin{array}{l}\text { Placebo } \\
(\mathbf{n}=\mathbf{7 9})\end{array}$ \\
\hline Any AE & $275(34.8)$ & $269(34.0)$ \\
Serious AEs & $44(5.6)$ & $54(6.8)$ \\
Serious AEs leading to death & $3(0.4)$ & $3(0.4)$ \\
Serious AEs not leading to death & $41(5.2)$ & $51(6.4)$ \\
Discontinuation of study treatment due to AEs & $46(5.8)$ & $91(11.5)$ \\
\hline
\end{tabular}

Notes: Safety population includes all patients who received at least one dose of treatment. This table includes patients with AEs onset during randomized treatment. Patients with multiple events in the same category are counted only once in that category. Patients with events in $>$ I category are counted once in each of those categories.

Table S4 Number (\%) of patients who had an adverse event (AE) in any category in the I2-month budesonide/formoterol vs placebo pool (Calverley et al and Szafranski et al studies only) ${ }^{1,2}$

\begin{tabular}{lll}
\hline Category of AE & $\begin{array}{l}\text { Budesonide/formoterol } \\
(\mathbf{n = 4 6 2 )}\end{array}$ & $\begin{array}{l}\text { Placebo } \\
(\mathbf{n}=\mathbf{4 6 I )}\end{array}$ \\
\hline Any AE & $284(61.5)$ & $270(58.6)$ \\
Serious AEs & $93(20.1)$ & $88(19.1)$ \\
Serious AEs leading to death & $10(2.2)$ & $10(2.2)$ \\
Serious AEs not leading to death & $85(18.4)$ & $80(17.4)$ \\
Discontinuation of study treatment due to AEs & $81(17.5)$ & $119(25.8)$ \\
\hline
\end{tabular}

Notes: Safety population includes all patients who received at least one dose of treatment. This table includes patients with AEs onset during randomized treatment. Patients with multiple events in the same category are counted only once in that category. Patients with events in $>$ I category are counted once in each of those categories. 
Table S5 Number (\%) of patients with most common adverse events (AEs) (frequency of $\geq 2 \%$ in any treatment group) in the 3-month budesonide/formoterol vs placebo pool (Welte et al, Calverley et al, and Szafranski et al studies) $)^{1,2,4}$

\begin{tabular}{llc}
\hline Preferred term & $\begin{array}{l}\text { Budesonide/formoterol } \\
(\mathbf{n}=\mathbf{7 9 1})\end{array}$ & $\begin{array}{l}\text { Placebo } \\
(\mathbf{n}=\mathbf{7 9} \mathbf{I})\end{array}$ \\
\hline Chronic obstructive pulmonary disease & $56(7.1 \%)$ & $103(13.0 \%)$ \\
Nasopharyngitis & $30(3.8 \%)$ & $26(3.3 \%)$ \\
Headache & $12(1.5 \%)$ & $7(0.9 \%)$ \\
Dysphonia & $14(1.8 \%)$ & $0(0.0 \%)$ \\
Pharyngitis & $4(0.5 \%)$ & $7(0.9 \%)$ \\
Pyrexia & $9(1.1 \%)$ & $1(0.1 \%)$ \\
\hline
\end{tabular}

Notes: This table includes patients with AEs onset during randomized treatment. Patients with multiple AEs coded to the same preferred term are counted only once for that preferred term.

Table S6 Number (\%) of patients with most common adverse events (AEs) (frequency of $\geq 2 \%$ in any treatment group) in the I2-month budesonide/formoterol vs placebo pool (Calverley et al and Szafranski et al studies only) ${ }^{1,2}$

\begin{tabular}{|c|c|c|}
\hline Preferred term & $\begin{array}{l}\text { Budesonide/formoterol } \\
(n=462)\end{array}$ & $\begin{array}{l}\text { Placebo } \\
(n=461)\end{array}$ \\
\hline Chronic obstructive pulmonary disease & $84(18.2 \%)$ & $125(27.1 \%)$ \\
\hline Nasopharyngitis & $42(9.1 \%)$ & 27 (5.9\%) \\
\hline Headache & $15(3.2 \%)$ & $10(2.2 \%)$ \\
\hline Pneumonia & $14(3.0 \%)$ & II (2.4\%) \\
\hline Chest pain & $16(3.5 \%)$ & $8(1.7 \%)$ \\
\hline Dyspnoea & $8(1.7 \%)$ & $15(3.3 \%)$ \\
\hline Back pain & $9(1.9 \%)$ & $9(2.0 \%)$ \\
\hline Muscle spasms & $14(3.0 \%)$ & $4(0.9 \%)$ \\
\hline Respiratory tract infection & $10(2.2 \%)$ & $7(1.5 \%)$ \\
\hline Diarrhoea & $9(1.9 \%)$ & $6(1.3 \%)$ \\
\hline Influenza & II (2.4\%) & $2(0.4 \%)$ \\
\hline Rhinitis & $10(2.2 \%)$ & $3(0.7 \%)$ \\
\hline Insomnia & $7(1.5 \%)$ & $5(1.1 \%)$ \\
\hline Myalgia & $8(1.7 \%)$ & $3(0.7 \%)$ \\
\hline Dysphonia & $9(1.9 \%)$ & I (0.2\%) \\
\hline Pharyngitis & $5(1.1 \%)$ & $5(1.1 \%)$ \\
\hline Pyrexia & $8(1.7 \%)$ & $2(0.4 \%)$ \\
\hline Dyspepsia & $8(1.7 \%)$ & I (0.2\%) \\
\hline Vomiting & 5 (I.I\%) & I (0.2\%) \\
\hline
\end{tabular}

Notes: This table includes patients with AEs onset during randomized treatment. Patients with multiple AEs coded to the same preferred term are counted only once for that preferred term.

\section{References}

1. Szafranski W, Cukier A, Ramirez A, et al. Efficacy and safety of budesonide/formoterol in the management of chronic obstructive pulmonary disease. Eur Respir J. 2003;21(1):74-81.

2. Calverley PM, Boonsawat W, Cseke Z, Zhong N, Peterson S, Olsson H. Maintenance therapy with budesonide and formoterol in chronic obstructive pulmonary disease. Eur RespirJ. 2003;22(6): 912-919.
3. Jenkins CR, Jones PW, Calverley PM, et al. Efficacy of salmeterol/ fluticasone propionate by GOLD stage of chronic obstructive pulmonary disease: analysis from the randomised, placebo-controlled TORCH study. Respir Res. 2009;10:59.

4. Welte T, Miravitlles M, Hernandez P, et al. Efficacy and tolerability of budesonide/formoterol added to tiotropium in patients with chronic obstructive pulmonary disease. Am J Respir Crit Care Med. 2009;180(8):741-750.
International Journal of COPD

\section{Publish your work in this journal}

The International Journal of COPD is an international, peer-reviewed journal of therapeutics and pharmacology focusing on concise rapid reporting of clinical studies and reviews in COPD. Special focus is given to the pathophysiological processes underlying the disease, intervention programs, patient focused education, and self management protocols.

\section{Dovepress}

This journal is indexed on PubMed Central, MedLine and CAS. The manuscript management system is completely online and includes a very quick and fair peer-review system, which is all easy to use. Visit $\mathrm{http}: / / \mathrm{www}$. dovepress.com/testimonials.php to read real quotes from published authors. 